\title{
Por Dentro da
}

Comunicação Interna

tendencias, reflexóes e ferramentas

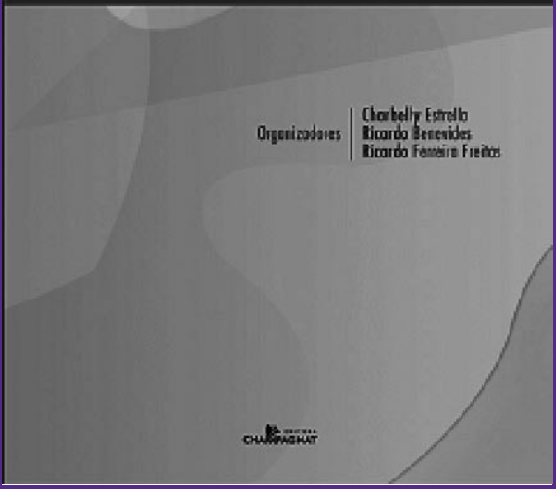

Por dentro da comunicação interna: tendências, reflexões e ferramentas

Charbelly Estrella; Ricardo Benevides; Ricardo Freitas (Org.)

Curitiba, PR:

Editora Champagnat, 2009

223 páginas

Resenhado por:

Valéria de Siqueira Castro Lopes

- Doutora em Ciências da Comunicação pela Escola de Comunicações e Artes da Universidade de São Paulo (ECA-USP)

- Mestre em Comunicação para o Mercado pela ECA-USP

- Graduada em Relações Públicas pela Universidade do Estado do Rio de Janeiro (UERJ)

- Professora dos cursos de graduação em Relações Públicas da ECA-USP e da Faculdade Cásper Líbero (Facásper)

- Docente do Curso de Pós-Graduação Lato Sensu de Gestão Estratégica em Comunicação Organizacional e Relações Públicas da ECA-USP

- Vice-presidente de Planejamento da Associação Brasileira de Relações Públicas - Seção de São Paulo (ABRP-SP)

- Autora de diversos capítulos de livros

- Sócia diretora da Mistura Fina Comunicação Organizacional

-valeria@misturafinacomunicacao.com.br 


\title{
A comunicação interna sob novos olhares
}

\author{
Internal communication \\ under new perspectives
}

\author{
La comunicación interna \\ bajo nuevas miradas
}

Os profissionais e acadêmicos que atuam em comunicação organizacional conhecem a relevância do público interno para o sucesso de uma organização - especialmente em cenários nos quais ocorrem mudanças constantes e a competitividade é acirrada, sendo o comprometimento e a motivação dos funcionários alguns dos elementos imprescindíveis à consecução de seus objetivos.

Embora a comunicação interna seja um tema de grande interesse, tanto para a academia quanto para o mercado, ainda são poucas as obras publicadas que se dedicam ao assunto. Por dentro da comunicação interna contribui para que essa lacuna seja suprida, uma vez que reúne artigos que discutem a gestão da comunicação interna diante das mudanças sociais e econômicas que impactam as relações de trabalho e o ambiente organizacional.

A primeira parte do livro, "Perspectiva histórica e teórica da comunicação interna”, é dedicada à reflexão sobre o impacto das transformações socioeconômicas na cultura e nos processos organizacionais, em particular no processo de comunicação com o público interno.

No primeiro artigo, "Desafios da comunicação interna: interferências da contemporaneidade", Ivone de Lourdes Oliveira e Maria Aparecida de Paula discutem a gestão da comunicação interna com base na reflexão sobre as mudanças sofridas pela sociedade ao longo do século XX e da primeira década do século XXI. As autoras confrontam as características da sociedade moderna e da sociedade contemporânea para, em seguida, apontar as contradições vivenciadas pelas organizações devido à manutenção, ainda na atualidade, de traços da empresa moderna. É a partir desse contexto que o artigo aborda a comunicação interna, propondo uma orientação estratégica desse campo da comunicação organizacional. 
No texto "O trabalho na contemporaneidade: da precariedade à inovação na comunicação organizacional”, Ricardo Ferreira Freitas discute os desafios da implantação de uma comunicação interna alinhada aos compromissos sociais assumidos pelas organizações e as perspectivas para a sua gestão. Para tanto, o autor faz um resgate histórico das relações de trabalho da Revolução Industrial até a atualidade, indicando as principais transformações sofridas pelos sistemas de produção e seus desdobramentos na relação e comunicação entre trabalhador e empresa.

Júlio Afonso Sá de Pinho Neto, em "Ética, cultura organizacional e responsabilidade social como fundamentos dos programas de relações públicas para o público interno", pauta a ética como compromisso organizacional em busca de princípios e modelos de administração comprometidos com os direitos dos trabalhadores. O autor defende que as ações de responsabilidade social de uma organização devam abarcar também o público interno para que possam ser legítimas, calcadas na ética e coerentes com o discurso organizacional.

O capítulo "Paradigmas de relações públicas: contribuições da teoria da complexidade para se pensar a comunicação interna nas organizações”, de Fátima Regis e Fernando Gonçalves, encerra essa parte do livro com um debate acerca da capacidade das abordagens funcionalista, estruturalista e dialética aplicadas às relações públicas em fornecer bases teóricas para a compreensão do relacionamento entre a organização com seu público interno. Regis e Gonçalves partem de uma análise da dinâmica social, à luz da obra $A$ corrosão do caráter: consequências pessoais do trabalho no novo capitalismo (Record, 1999), de Richard Sennet, para evidenciarem como as relações de trabalho passaram a ser pautadas pela transitoriedade e pelo risco. Em seguida, discutem o impacto que tais alterações provocam no mercado de trabalho, em especial na formação do profissional de relações públicas. O artigo é concluído com a proposição da teoria dos sistemas complexos como um paradigma capaz de fornecer arcabouço teórico às relações públicas para lidar com a comunicação interna nesse novo contexto.

Na segunda parte, a obra reúne textos voltados à análise e à discussão das práticas de comunicação interna, considerando a sua correlação com fatores como ética empresarial, cultura e clima organizacional. O capítulo "Comunicação face a face”, de Mônica Cristina Fort, Arilton Rocha de Sousa, Bogodar Kuczynski Filho e Roberto Aparecido Mancuzo Silva Júnior, aponta a comunicação interpessoal como estratégia relevante para a humanização do processo de comunicação na era da tecnologia da informação com base no estudo de casos.

A ética é novamente pautada no artigo de Ricardo Benevides, "Ética nas relações com funcionários", no qual o autor dá diretrizes para a elaboração de um código de ética orientado pela coerência entre valores e conduta organizacional. No capítulo seguinte, "A importância do público interno na comunicação institucio- 
nal”, Chaberlly Estrella e Rosane Fernandez defendem a comunicação dirigida a esse público como sua atividade mais importante, abordando especificamente os eventos como valiosa estratégia no relacionamento com esse público.

"Marketing, marketing interno e comunicação nas organizações”, de João Renato Benazzi, procura debater a interface entre comunicação e administração na busca por uma comunicação integrativa, que priorize a perspectiva do indivíduo. No capítulo "Comunicação empresarial e gestão de mudanças organizacionais”, Ana Paula de Avellar Mattos analisa o caso do voluntariado do Instituto Nacional do Câncer para ressaltar a importância da comunicação na condução de mudanças organizacionais. Encerrando a obra, Bruno Cunha e Eneida Leão orientam o leitor na construção de textos e na adequação de conteúdos aos mais diferentes veículos de comunicação interna em seu artigo "Vale o que está escrito".

Os textos da coletânea Por dentro da comunicação interna convergem em vários pontos. No entanto, deve-se destacar a abordagem crítica dos artigos, muitas vezes de tom provocativo, que nos instigam a refletir sobre nossas práticas e a buscarmos a permanente renovação. 